DOI: $10.4274 /$ tpa.46.43

\title{
Puberte gecikmesi
}

Delayed Puberty

Zehra Aycan

Sami Ulus Kadın Doğum Çocuk Sağığı ve Hastalıkları Eğitim ve Araştırma Hastanesi, Ankara, Türkive

\section{Özet}

Puberte, ergenin gelişiminde fiziksel ve psikolojik olarak oldukça önemli bir dönemdir. Pubertenin başlaması beslenme , etnik grup ve genetik başta olmak üzere birçok etkene bağlı olarak değişebilmektedir. Puberte genellikle kızlarda 8, erkeklerde 9 yaşından itibaren başlayabilir ve yaklaşık olarak kızlarda 3.5, erkeklerde 2.5 yılda tamamlanmaktadır. Gecikmiş puberte kızlarda 13, erkeklerde 14 yaşında ikincil cins karakterlerinin başlamaması olarak tanımlanabilir. En yaygın sebebi yapısal büyüme ve puberte gecilmesidir. Bu durum erkeklerde yaygındır ve aileseldir ki aynı cinsiyetteki ebeveyninde benzer durum vardır. Tipik olarak sağlıklı çocuklardır ve kronolojik yaşa göre boy kısalığı ve puberte gecikmesi vardır, fakat bu gecikme kemik yaşı ile uyumludur. Gecikmiş puberte plazma luteinizan hormon ve follikül stimulan hormon düzeylerine göre sınılandırılabilir. Santral Sinir Sistemi anomalileri sonucu oluşanlar hipogonadotropik hipogonadizm, gonadal yetersizlik sonucu olanlar ise hipergonadotropik hipogonadizm olarak tanımlanabilir. Yapısal puberte gecikmesi ile patolojik puberte ayırıcı tanısı yapabilmek için ilk basamak detaylı öykü almaktır. İleri incelemede ise laboratuvar testleri (östradiol, testosteron, GnRH testi, karyotip analizi) ve görüntüleme çalışmaları (sol el ve bilek grafisi, gonad USG, gerekirse MRI) yapılarak ayırıcı tanıya gidilmelidir. Tedavi nedene yönelik olarak kısa ve uzun dönemli olabilir. Gecikmiş puberte ve diğer pubertal problemlerin erken tanımlanıp doğru tanı konulması ve Çocuk Endokrinoloji Uzmanı tarafından uygun tedavi edilmesi önerilmektedir. (Türk Ped Arş 2011; 46 Özel Sayı: 88-91)

Anahtar sözcükler: Gecikmiş puberte, tanı, tedavi

\section{Summary}

Puberty is a quite important phase in the physical and psychosocical development of the adolescent. The timing of puberty is variable and is dependent on several factors including ethnic group, nutrition and genetic factors. It may commence from 8 years of age in girls and 9 years in boys and is usually complete after 3,5 years in female and 2,5 years in males. Delayed puberty is defined as the lack of secondary sexual characteristics from the age of 13 years in females and 14 years in males. The most common cause is constitutional delay in growth and puberty. It is more common in boys and most cases are familial, usually occurring in the same-sex parent. This typically occurs in healthy children who have delayed puberty with short stature for their chronological age, but this delay is appropriate for the bone age. Pubertal delay can be classified according to circulating levels of luteinizing hormone and follicle stimulating hormone. Central nervous system abnormalities result in hypogonadotrophic hypogonadism and gonadal failure causes hypergonadotrophic hypogonadism. A detailed history is the first step in the diagnostic evaluation of a constitutional delay and abnormal puberty. Further evaluation includes laboratory testing (estradiol, testosterone, the results of a GnRH test, karyotip analysis ) and imaging studies (X-ray of the left hand and wrist, USG of the gonads, MRI ). Treatment is directed at both the acute and long-term consequences of delayed or absent pubertal development. Delayed puberty and other pubertal disorders should be recognized early, correctly diagnosed by a pediatric endocrinologist, and appropriately treated. (Turk Arch Ped 2011; 46 Suppl: 88-91)

Key words: Delayed puberty, diagnosis, treatment

Yazışma Adresi/Address for Correspondence: Dr. Zehra Aycan,

Sami Ulus Kadın Doğum Çocuk Sağlığı ve Hastalıkları Eğitim ve Araştırma Hastanesi, Ankara, Türkiye E-mail: zehraaycan67@hotmail.com Türk Pediatri Arşivi Dergisi, Galenos Yayınevi tarafindan basilmıştı. / Turkish Archives of Pediatrics, Published by Galenos Publishing. 


\section{Giriş}

Pubertal zamanlama başta genetik etkenler olmak üzere etnik grup ve beslenme ile yakından ilişkilidir. Puberte normalde kızlarda 8, erkeklerde 9 yașında bașlayabilmekte ve ortalama kızlarda 3,5, erkeklerde 2,5 yılda tamamlanmaktadır (1). Pubertal başlangıç kızlarda telarşın evre 2 olması kabul edilirken, erkeklerde testis volümünün 4 ml'ye ulaşması olarak tanımlanmaktadır. Hipotalamustan gonadotropin salgılatıcı hormonun $(\mathrm{GnRH})$ pulsatif olarak salgılanmaya başlaması sonucu hipofizden LH ve FSH salınımı artmakta ve over / testis hücrelerine olan uyarı sonucu östrojen ve testosteron hormonu salgılanmaktadır. Kisspeptin ve G protein coupled reseptor 54 (GPR54) GnRH nöronlarının pubertal aktivasyonunda önemli rol oynar. Bununla birlikte GABA ve opioid nöronlar GnRH salınımını inhibe ederken, glutamat ve glial hücreler uyarıcıdılar. Kisspeptin ve reseptörlerinin olmaması, ya da $\mathrm{GnRH}$ salınımını inhibe eden maddelerin herhangi bir nedenle artışı puberte gecikmesine neden olurken kisspeptin reseptörlerinin aktive edici mutasyonları ve aktivatör maddelerin artışının erken puberteye yol açabileceği düşünülmektedir. Bu konuda kapsamlı çalışmalara intiyaç vardır. Pubertenin başlaması devam edebilmesi, cinsel olgunlaşmanın sağlanması ve fertilitenin kazanılması hipotalamo-hipofizer gonad ekseninin sağlıklı çalışmasına bağlıdır. Bu eksenin konjenital ya da edinsel; organik ya da işlevsel sorunları pubertal sorunların başlıca nedenidir.

Gecikmiş puberte; kızlarda 13 yaşın bitmesine rağmen meme tomurcuklanmasının (meme evre 2) başlamamış olması, erkekte ise 14 yaşın tamamlanmasına rağmen testis volümünün 4 ml'ye (genital evre 2) ulaşmaması olarak tanımlanabilir. Gecikmiş puberte hem ergenin kendisi hem de ailesi için önemli bir stres kaynağıdır.

\section{Gecikmiş puberte 3 ana neden ile oluşmaktadır:}

1- Yapısal puberte ve büyüme gecikmesi

2- Hipogonadotropik hipogonadizm (santral, fonksiyonel)

3- Hipergonadotropik hipogonadizm

Gecikmiş pubertenin etyolojik dağılımına baktığımızda \%63-70 oranında yapısal puberte ve büyüme gecikmesi yer almakta, fonksiyonel hipogonadizm \%20, kalıcı (santral) hipogonadizm \%9, hipergonadotropik hipoganadizm ise \%7 sıklıkta görülmektedir (2).

1. Yapısal puberte ve püyüme gecikmesi: Genellikle erkeklerde görülen bu durumda $\% 80$ ailesel yatkınlık vardır; \%46 tek ebeveynde \%33 her iki ebeveynde de yapısal puberte gecikmesi olasılığı mevcuttur. Ilımlı boy kısalığı ve zayıflıkları olan bu çocukların pubertal yaşa geldiklerinde pubertal boy sıçramasını zamanında yapamadıkları için büyüme eğimlerindeki yerleri 3. persentil altına düşebilir, ancak final boyları genellikle hedef boyları ile uyumludur (3). Büyüme hızları normal olan olguların üst vücut segmentleri pubertenin gecikmesi sonucu daha kısadır. Sağlıklı olan çocuklarda pubertenin neden geciktiği sorusunun yanıtı tam olarak alınmış olmamakla birlikte $\mathrm{GnRH}$ reseptör mutasyonları, LH reseptör gen polimorfizmi, leptin ve reseptörlerinin mutasyonları, FGFR1 mutasyonu ile ilgili çalışmalar devam etmektedir (4).

2. Hipogonadotropik hipogonadizm: Hipotalamohipofizer (organik ya da işlevsel) hastalıkların yanı sıra bazı sendromik hastalıklarda bu grupta yer alır. Tablo 1'de hipogonadotropik hipogonadizm nedenleri ayrıntılı olarak verilmektedir.

İntrauterin dönemde GnRH nöronlarının olfactor bulbustan hipotalamusa göçü KAL gen ve ürünü Anosmin-1 tarafından yapılmaktadır ki bu gen mutasyonlarında Kallman Sendromu oluşur. Hipogonadotropik hipogonadizm ve anosmi/hiposmi

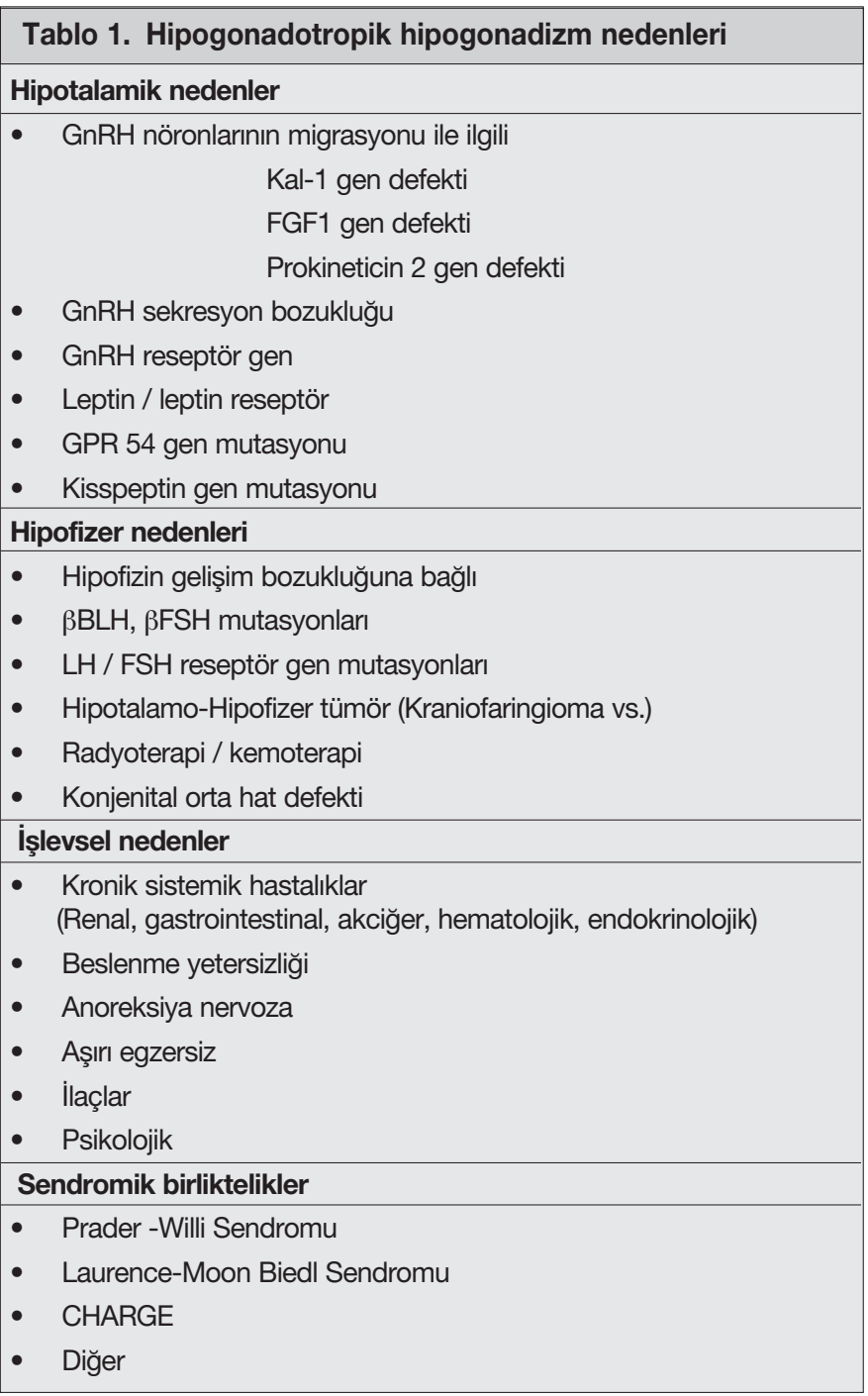


ile karakterize olan Kallman Sendromu erkeklerde 1/800010000, kızlarda 1/50000 sıklıkta görülür. Klasik başvuru yakınması pubertenin başlamaması olan hastalarda, yenidoğanlarda mikropenis, kriptorşidizm olabileceği gibi renal aplazi / hipoplazi, yüksek damak, sensorinöral işitme kaybı, dental ve fasiyal sorunlar da eşlik edebilir. Prader Willi ve Laurence Moon Biedl sendromunda şişmanlık ve hipogonadotropik hipogonadizm, boy kısalığı birlikteliği vardır. Hipofizin gelişiminden sorumlu olan birçok gen (LHX3/4, HESX-1, PROP-1, PIT 1) mutasyonlarında da hipogonadotropik hipogonadizm oluşabilir. Organik nedenlerin yanı sıra Tablo 1'de görüldüğü gibi birçok ikincil neden; kronik hastalıklar, yeme bozuklukları, aşırı egzersiz, radyoterapi / kemoterapi uygulamaları ve psikolojik stres durumları hipotalamo-hipofizer hormonlarda işlevsel bozukluğa neden olarak pubertenin gecikmesine ya da duraklamasına neden olabilmektedir.

3. Hipergonadotropik hipogonadizm: Hipotalamohipofizer eksen intakt olmasına rağmen primer gonadal yetmezlik sonucu oluşur. Parsiyel ya da inkomplet olgularda puberte başlayabilir ancak devamı sağlanamaz. Primer gonadal yetmezliklerde gonadotropinler özellikle FSH çok yüksektir ve bu yükseklik 8-9 yaşından itibaren belirginleşmeye başlar. Bu hastalarda kuşkulu genitalya olmazsa bile karyotip analizi yapılması önerilmektedir. Ayrıca Pelvik ultrasonografi (USG) iç genital yapının belirlenmesi ve

Tablo 2. Hipergonadotropik hipogonadizm nedenleri

\begin{tabular}{|c|c|}
\hline KIZ & ERKEK \\
\hline $\begin{array}{l}\text { Kromozom anomalileri } \\
\text { Turner Sendromu } \\
\text { Mix gonadal disgenezi }\end{array}$ & $\begin{array}{l}\text { Kromozom anomalileri } \\
\text { Klinefelter ( } 47 X X Y \text { ve varyantları) } \\
\text { Mix gonadal disgenezi }\end{array}$ \\
\hline $\begin{array}{l}\text { Gonadal gelişim anomalileri } \\
\text { Overian disgenezi }\end{array}$ & $\begin{array}{l}\text { Gonadal gelişim anomalileri } \\
\text { Testiküler disgenezi }\end{array}$ \\
\hline $\begin{array}{l}\text { Steroid sentez ve etki bozuklukları } \\
\text { FSH / LH direnci } \\
\text { Pseudohipoparatiroidizm 1a } \\
\text { (46XX)-SF-1, StAR, CYP 11a, } \\
\text { CYP 17, aromataz } \\
\text { (46XY)-HSD17B2, AIS,5RD5A2 }\end{array}$ & $\begin{array}{l}\text { Sendromik birliktelikler } \\
\text { Noonan Sendromu } \\
\text { Robinow Sendromu } \\
\text { Diğer }\end{array}$ \\
\hline $\begin{array}{l}\text { Diğer overian yetmezlikler } \\
\text { Otoimmun hastalık } \\
\text { Hiperandrojenizm / PCOS }\end{array}$ & $\begin{array}{l}\text { Steroid sentez / Etki problem } \\
\text { LH direnci } \\
\text { SF-1, StAR, CYP11a }\end{array}$ \\
\hline $\begin{array}{l}\text { Pelvik Radyoterapi } \\
\text { Kemoterapi }\end{array}$ & $\begin{array}{l}\text { Primer testiküler yetmezliğin } \\
\text { diğer nedenleri } \\
\text { Anorşi } \\
\text { Kriptorşidizm } \\
\text { Sertoli cell only Sendromu } \\
\text { Testiküler irradiasyon } \\
\text { Kemoterapi } \\
\text { Enfeksiyon ( Kabakulak) }\end{array}$ \\
\hline
\end{tabular}

gonadların morfolojilerini tanımlamak bakımından önemlidir. İyi görüntülenmeyen olgularda Manyetik Rezanans (MRI) ve sintigrafi de yapılmalıdır. Gereken olgularda hCG testi ile gonadal ișlevler değerlendirilmelidir. Hipergonadotropik hipogonadizme neden olan hastalıklar Tablo 2'de verilmiştir.

Turner Sendromu kızlarda en sık rastlanan gonadal yetmezlik nedeni olup, 2500 canlı kız doğumda bir görülür. $\mathrm{X}$ kromozomunun tam ya da kısmi kaybı söz konusu olduğundan overian disgenezi söz konusu olup, sendroma puberte yokluğu ya da gecikmesi yanında kısa boy, yele boyun, diğer sistemik hastalıklar da (kardiyak, renal vs) eşlik etmektedir.

Klinefelter Sendromu ise erkek hipergonadotropik hipogonadizmin sık görülen nedenlerinden olup, X kromozom fazlalığı (47XXY ve varyantları) ile karakterizedir. Uzun boylu, önikoid yapıda olan bu erkeklerde testis işlevleri puberteyi başlatmasına rağmen ilerlemesi ve tamamlanmasında yetersiz kalmaktadır. Seminifer tübüllerde disgenezi ile karakterize sendromda hipospadias, ufak sert testisler, azospermi ve jinekomasti görülebilir. Sıklıkla davranış problemleri ıımlı mental retardasyon eșlik edebilir.

Gecikmiş puberte ile başvuran hastalarda tanıya gidebilmek için tüm hastalıklarda olduğu gibi dikkatli bir öykü alınması önemli ipuçları sağlayacaktır. Öyküde ailede puberte gecikmesi olup olmadığı en sık görülen yapısal puberte gecikmesini tanımlamada önemlidir. Sistemik hastalık, infertilite varlığı, otoimmün hastalıklar, geçirilmiş ameliyatlar (fitık, orşiopeksi vs.) radyoterapi/kemoterapi öyküsü, koku alma problemleri (Kallman Sendromu), doğum ve gebelik öyküsü, yeme problemleri dikkatli bir şekilde sorgulanmalı ve sonrasında beden ölçüleri (boy, ağırlık, gerekirse üst/alt beden oranı vs.) değerlendirilmeli ve tam sistemik muayene ile birlikte dikkatli bir genital muayene yapılmalıdır. Laboratuvar tetkiklerinden ilk yapılması gereken serum LH / FSH / E2 ve testosteron düzeylerine bakllarak hipogonadotropik/hipergonadotropik hipogonadizm ayırımını yapmaktır. Sonraki aşamada ise gerekirse LH-RH, hCG uyarı testleri, gonadal görüntüleme ve karyotip analizi yapılabilir (5). Gecikmiş pubertede tanıya yönelik algoritma Şekil 1'de verilmiştir (1).

Tedavide östrojenin ve testosteronun yerine konması önerilmektedir $(1,4,6)$. Tedaviye hangi yaşta bașlanacağı konusunda tam bir görüş birliği bulunmamakla birlikte 13-14 yaşlarında ve düşük dozlarla başlanması önerilmektedir. Erken başlanan tedavilerde, özellikle yüksek dozlarda epifizlerin erken kapanması sonucu boy potansiyeli negatif etkilenebilmekte, gecikmiş tedavilerde ise osteoporoz riskinin yanı sıra psikolojik problemler de görülebilmektedir.

Erkeklerde yapısal puberte ve büyüme gecikmesinde; yaşı 14 olduğu halde testis volümü 3-4 ml'den küçük, boyu 2 SD' nun altında ve sabah serum testosteron düzeyi $100 \mathrm{ng} / \mathrm{dl}$ 'nin altında olanlarda, testosteron depo enjeksiyonundan 3 haftada bir 50-200 mg dozda toplam 4-6 doz 


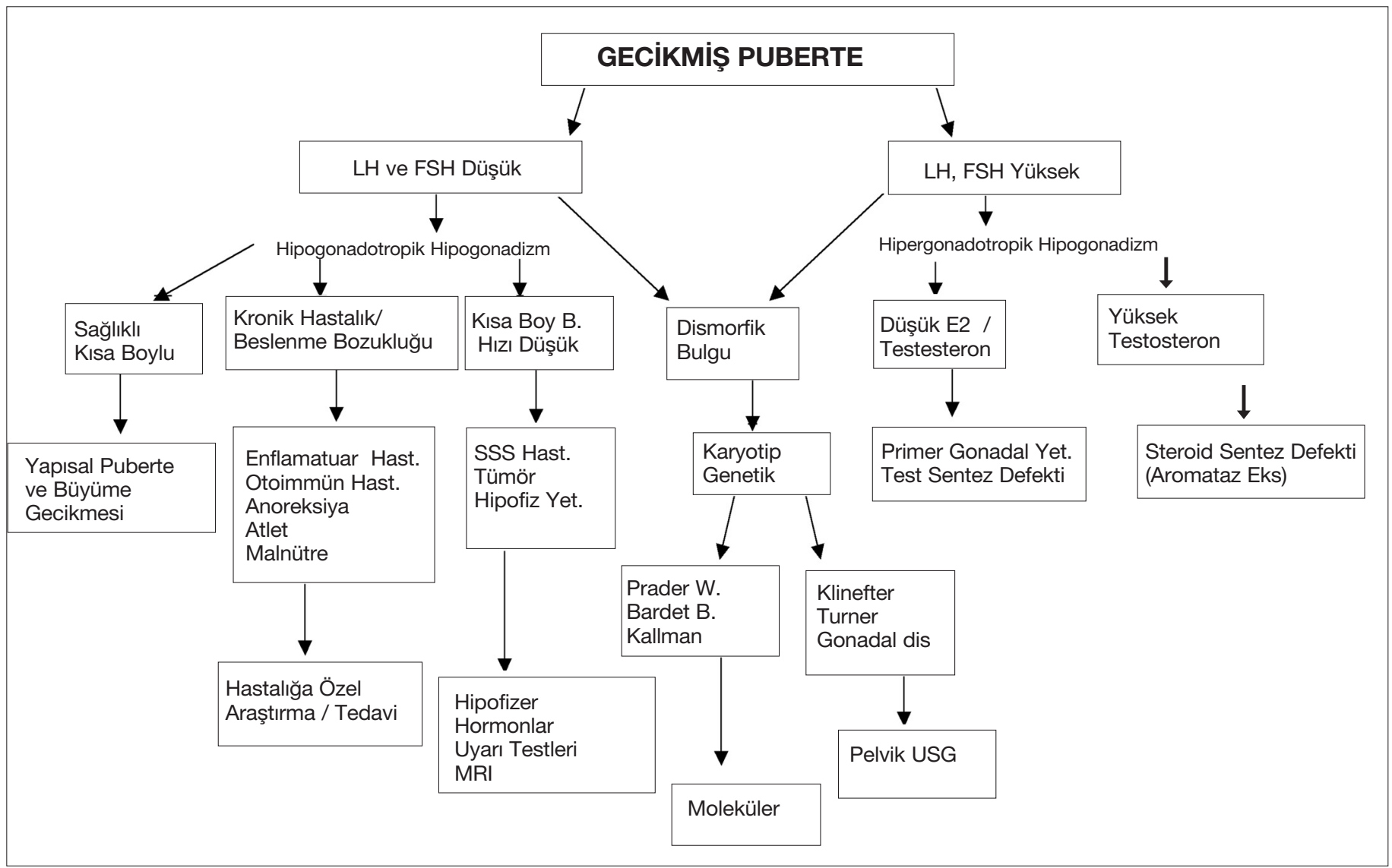

Şekil 1. Gecikmiş pubertede tanısal yaklaşım

yapılması önerilmektedir. Kızlarda ise etinil östradiol 10 mg/gün 3 ay süreyle uygulanabilmektedir. Bu tedavi ile pubertal tetiklenme hedeflenmekte ve boyda küçük bir sıçrama yaşanmaktadır.

Kalıc hipogonadotropik ve hipergonadotropik hipogonadizmde; kızlarda düşük doz östrojen tedavisi (2 $\mu \mathrm{g} / \mathrm{gün}$ ethinylestrodiol) ile başlanır, her 6-12 ayda $2 \mu \mathrm{g}$ artırılarak, 2. yılda progesteron tedaviye eklenir. Erkeklerde testosteron enanthat 50-100 mg/4 haftada bir depo enjeksiyon şeklinde başlanır, pubertal gelişimin bitiminde $250 \mathrm{mg} / 3$ haftada bir şeklinde devam edilir. Alternatif olarak oral testosteron undecanoate 20-40 mg/gün başlanıp, 80-240 mg/gün'e kadar çıkabilir ve cinsel etkinlik normale ulaşana kadar bu dozda devam edilir.

\section{Kaynaklar}

1. Mushtaq T, Wales JK. Diagnosis, investigation and treatment of delayed puberty in children. Pediatr and Child Health 2007; 17: 349-55. (Abstract) / (Full Text) / (PDF)

2. Sedlmeyer IL, Palmert MR. Delayed puberty: analysis of a large case series from an academic center. J Clin Endocrinol Metab 2002; 87: 1613-20. (Abstract) / (Full Text) / (PDF)

3. Cools BL, Rooman R, Op De Beeck L, Du Caju MV. Boys with a simple delayed puberty reach their target height. Horm Res 2008; 70: 209-14. (Abstract) / (Full Text) / (PDF)

4. Brämswig J, Dübbers A. Disorders of pubertal development. Dtsch Arztebl Int 2009; 106: 295-303. (Abstract) / (Full Text) / (PDF)

5. Traggiai C, Stanhope R. Delayed puberty. Best Pract Res Clin Endocrinol Metab 2002; 16: 139-51.

6. Ambler GR. Androgen therapy for delayed male puberty. Curr Opin Endocrinol Diabetes Obes 2009; 16: 232-9. (Abstract) 